\title{
Online Forum Discussion to Promote Sense of Learning Community among the Group Members
}

\author{
Maslawati Mohamad ${ }^{1} \&$ Shahizan Shaharuddin ${ }^{2}$ \\ ${ }^{1}$ Faculty of Education, Universiti Kebangsaan Malaysia, Malaysia \\ ${ }^{2}$ Centre of Liberal Studies (CITRA), Universiti Kebangsaan Malaysia, Malaysia \\ Correspondence: Maslawati Mohamad, Faculty of Education, Universiti Kebangsaan Malaysia, 43600 UKM \\ Bangi, Selangor, Malaysia. Tel: 601-3327-0680. E-mail: maslawati@ukm.edu.my
}

Received: July 22, 2014 Accepted: November 5, 2014 Online Published: December 21, 2014

doi:10.5539/ies.v7n13p61

URL: http://dx.doi.org/10.5539/ies.v7n13p61

\begin{abstract}
The integration of e-learning within a distance learning program helps to foster greater interaction among learners who are geographically distant from one another. Various ways have been implemented to achieve this aim, one of which is the use of online forum. Research shows that the use of online forum is capable of fostering a sense of learning community among learners. However, much remains to be known about what happens when adult learners in a distance learning program participate in an online forum as means to improve their reading comprehension in English and promote learning of the subject matter. This article discusses the use of online forum discussion in English for Life Sciences distance learning course. It demonstrates that the online forum discussion practiced in the course was useful in developing a sense of learning community. In this case it can be concluded that knowledge of both the subject matter and the language is constructed collaboratively among the adult learners. The article also discusses the implications of the study for the educators involved.
\end{abstract}

Keywords: e-learning, online forum, adult learners, writing

\section{Introduction}

The concept of learning community is very important for many distance learning programs particularly when the learners are geographically apart from each other. Distance learners (DL) need to communicate with each other in order to have a sense of belonging and community; therefore reducing the number of dropouts (Inoue, 2007). The concept of distance learning has existed for many years in Malaysia (Hisham \& Rozhan, 2003), but at present distance learning program has evolved to integrate e-learning concept in order to reduce cost for both parties: the educators (DE) and the distance learners (DL). Moreover, the integration of technology in Malaysia's education system is becoming increasingly important at both personal and professional levels (Dudeney \& Hockly, 2007). Educators must be aware that the focus is not only on how technology can be used to achieve educational goals but also on the human aspects of teaching and learning (Kadir \& Din, 2006). Due to that, many elements have since been incorporated into distance learning program to take advantage of its benefits. These include the use of online forum as a way to utilize technology in education, as well as enhancing teaching and learning. It is believed that online forum enables the creation of a learning community that is important for fostering learning, yet could be lacking in distance learning programs. It is imperative that educators who need to design an e-learning course for distance learners be aware of how online forum discussion could promote a sense of community among distance learners and the teacher's roles in managing the online forum discussion. Thus, this study was embarked to investigate these issues. It is hoped the findings could provide better insights on how both the course designers and distance learning educators (DE) could integrate online forum to develop effective learning community.

\section{Background}

As e-learning is likely to stay in Malaysia's education system, both educators and students need to prepare themselves for the new developments in language teaching technology, and have no choice but to adapt to the rapid technological changes (McKenzie \& Murphy, 2000). It is necessary at this point to provide background information on the development of online courses in Malaysia so that the importance of online learning for DL, particularly adult learners, can be well understood. The need for online education is more prominent after the 
announcement of the Third Outline Perspective Plan 2001-2010 (Government of Malaysia 2001). In this latest development of Malaysia's education plan, Malaysia has taken the initiative to embark on lifelong learning, of which online learning plays a key role. Malaysia former Prime Minister, Tun Abdullah Ahmad Badawi views lifelong learning as an important element in a knowledge-based economy where knowledge and skills are continuously updated and upgraded. Inoue $(2007$, p. 3) posits the concept of lifelong learning as "activities people perform throughout their lives to improve their knowledge, skills, and competence professionally, socially and personally". The Malaysian educators who are the key players in the education industry play an important role in materializing the planned objectives. This can be witnessed from the efforts shown by local universities. Therefore, Malaysian government policy changes have resulted in many higher institutions offering courses for adult learners to help them upgrade their education level while still maintaining their jobs. Moreover, education nowadays should also strive to fulfill the needs and personalities of the students (Martin et al., 2007).

Most adult learners register for an online course because they have to combine jobs with part-time study and family life (Ramesh \& Sanjaya, 2007). The main reason is many adult learners could not afford to quit their job due to financial constraints and family commitments. This explains the reason why distance education has become a dominant mode of higher education among adult learners. They are only required to attend limited face-to-face classes and spend more time on e-learning mode. These adult learners are scattered all over Malaysia and the communication tools among their fellow classmates and lecturers or facilitators are through emails, telephone calls and online forums.

The integration of online forum as a medium of discussion is essential to overcome the spatial and temporal barriers as to promote collaborative learning (McKenzie \& Murphy, 2000). Online forum allows the students the opportunity to communicate beyond the boundary of the classrooms, at any time of the day (Collis \& Moonen, 2006). Sometimes, students are enthusiastic to read and write but other times they might not have the time or the interest. Therefore, online forum provides them the facility to plan their reading and writing at their own convenient time. Online communication can be divided into two: synchronous and asynchronous (Hisham \& Rozhan, 2003). Synchronous refers to a platform whereby the communicators, DL and DE, communicate with each other in real time. In contrast, the communicators could also communicate with each other in delayed time, or asynchronous. Both forms of communication can be used depending on their preferred time, individual lifestyles, and learning preferences. These innovations provide flexibility and convenience to the students as they juggle family commitments and workplace demands. The incorporation of online discussion also provides opportunities and avenues for DL to share their knowledge, concerns, doubts and difficulties with fellow classmates and also the educator. The students need to create rapport among themselves and with the educator to avoid the feeling of isolation and lack of motivation (Inoue, 2007). Other scholars, Hisham and Rozhan (2003), also highlighted that one of the contributing factors that motivates the DL to succeed is the degree of interaction among themselves.

\section{Research Questions}

In developed countries such as United States of America, Australia and Britain, the educational benefits derived from an e-learning community via online forum have been well studied and documented. However, in the Malaysian context, the empirical evidence is still scarce. For this reason, several UKM researchers decided to carry out a study to look more closely into the benefits of the use of online forum in the context of a local academic institution. The following are the main research questions formulated in the study:

How does online forum discussion create a sense of learning community?

What is the educators' role in maintaining an e-learning community?

It is hoped that the findings of this case study can be applied to generate new insights into the design of e-learning and teaching practices, as well as the overall adult learners' learning experience. The following section discusses the underpinning theory within the context of this study.

\section{Literature Review}

\subsection{Theoretical Framework}

The underpinning theories behind the online forum discussion are constructivist, behaviorist and cognitive theory. Under constructivist theory, it presumes that students monitor and participate actively in their own learning process (Jonassen, 1994). When they are in control of their own learning process they would perform better and achieve better results (Toh, 2003). In any e-learning programs or courses, technology is employed. The e-learning course of this study which is English for Life Sciences promotes flexible and self-regulated learning allowing students to take control of their learning and becoming more involved in decision-making with respect 
to their own learning. Constructivists advocate that knowledge is constructed not transmitted. The constructivists namely Dewey (1963) and Vygotsky (1978) also advocate that learning should be a social process. The discussion via online forum enables the students to construct knowledge and be involved in the social process of learning simultaneously. In this regard, in order to answer the online forum questions, students did not simply regurgitate information they assemble in the websites but transformed the information using their critical thinking and higher order thinking skills like classifying and reasoning, analyzing errors, constructing support and analyzing perspectives.

The type of approach to be adopted is very much dependent on the context of learning, thus course designers should not negate the application of other theories such as behaviorist and cognitive theories to learning. In line with the behaviorists' view, the ELS teachers, for example, should prepare grammar notes and explanations to equip their students with the knowledge on word phrase, and sentence structure (Alessi \& Trollip, 1991). With online forum, although construction of knowledge is key consideration, the use of linguistic notes would help in the learning and practice of grammar and sentence construction, especially for the weaker students. In the course focused on in the study, the student participants were given linguistic notes on tenses, conjunctions, transitions, cohesive devices, prepositions, prefixes and suffixes, types of sentences and subject-verb agreement that helped them in the writing and editing process. The online aspect of the course is to assist teachers in providing rewards in the form of marks for participation in the online forum discussion. It is noted in the findings to be discussed later that the use of positive reinforcements such as this helped to break down barriers associated with online communication for the older learners, indirectly supported the social process that is needed to carry out online forum discussions.

Cognitivists believe that human learn in linear form (Jordan et al., 2008). Humans go through a few stages when they develop their intellectual capacity but it does not stop when the learners reach a certain age (Rogers, 2002) or a certain stage (Lantolf \& Thorne, 2006). At the initial stage, these novice learners read the given linguistic notes and other relevant reading materials for schema assembly and integration. Rogers (2002) adds that in order for a person to learn, he must first need to understand. At the following stage they integrated both linguistic knowledge and content knowledge to write on the subject matter. Then, they revise and rewrite. Only when the students have both linguistic and content knowledge a constructivist approach could be adopted. At this level, the students are able to make complex and intelligent decision using higher level thinking skills (Cheong, 2008).

\subsection{Learning Community}

According to Sarason (1974), people develop a sense of community when they share similarities with regard to perception. They also develop a sense of interdependence with each other whereby they are committed to take part and contribute to the community. In 1986, two prominent psychologists, McMillan and Chavis (1986) gave another definition of sense of community. They identified sense of community as a group of people who have a sense of belonging with the group members and they also develop and display a sense of commitment to the wellbeing of others. When online communication expands due to e-learning activities, both educators and students start to develop an e-group to fulfill their academic interest, needs and requirements. Parallel to the idea of e-learning groups, Hardman (2003) identified e-learning community as referring to a group of people who are connected via technology-mediated communication. Within the learning group, they share a social bonding and work collaboratively to accomplish learning goals through student-centered activities.

The significance of learning community in online learning is highlighted in many studies. One of the main significance of a learning community is its ability to heighten students' satisfaction. For a start, developing a sense of learning community among distance learners is required as distance learners by nature work in isolation. There is therefore, the need to create an environment that could facilitate the development of a classroom learning community. Within that space provided by a learning community, learning occurs through reflection, construction of meaning and mutual understanding; within a social environment. Fostering a sense of learning community is important for several reasons. According to Shackleford and Maxwell (2012), a sense of learning community facilitates interaction, social reinforcement and information exchange required for learning to take place. With reference to online discussion, research show that online discussion has been found to be effective in developing this sense of learning community, especially for DLs. What happens is that the social nature of the online discussion/participation helps connect one another through information sharing and support. In terms of interaction, studies have shown that interaction correlates positively with students' sense of learning community. Interaction involves three elements which are learner-instructor, learner-content, and learner interface (Shackelford \& Maxwell, 2012). However, this paper only looks into the importance of learner-instructor in maintaining an e-learning community. 
Distance educators (DE) have a role to play in supporting and maintaining a learning community. Boyd and Murphrey (2002) proposed that an educator should ascertain that the designed asynchronous forum promote higher order thinking skills. The Bloom taxonomy separates thinking skills into six hierarchical categories: knowledge, comprehension, application, analysis, synthesis, and evaluation (Bloom, 1956). A DE should design instructions which require the DLs to go beyond than merely understanding the reading materials but to work with others to complete a project or solve an issue. At the end of the lessons, the DLs should be able to create something new or propose new solutions to an issue. The issue in this context should emulate the adult learners' workplace situations. The first two levels of higher order thinking skills advocated by Bloom's taxonomy are knowledge and comprehension. The DLs could acquire both levels effectively when they read extensively on the discussed topic and build their knowledge by working collaboratively with their e-learning community to further enhance their understanding. In order to achieve this, the DE should pose a question which requires the DLs to read extensively, share their understanding with other classmates, share website links and other relevant materials pertaining to the discussed topic (i.e. lecture notes, video clips, pictures), and correct the misconception of others. At the initial stage, the DE should inform the DLs the ethics of e-learning community. For example, they should not use harsh words, post any remarks which intimidate others, and give comments which are sensitive to others' religion and race. As Malaysia is a melting pot of many races, the DE needs to announce that the DLs should respect other races' culture and religion. In conclusion, when the DLs are able to recall terminology, facts and other previous knowledge, they are able to acquire the most basic thinking skill which is knowledge. When the DLs explain and discuss with each other the terminologies, facts, new information and their previous knowledge, they are able to develop comprehension.

The following levels of Bloom taxonomy are application and analysis. Application category refers to when the students are able to relate the new learned information with their previous knowledge and apply it in new and concrete situations to solve a problem (Bloom, 1956). In this aspect, the DE should ask the DLs to work collaboratively to inter relate the new information which they gathered from their readings and discussion with their own existing knowledge. As all the DLs are working adults, they should relate the new learned information with their work experience and prior knowledge which they obtained during their Diploma. Analysis takes part when the information or knowledge is then rearranged, selected, and applied to solve a problem, complete a project or find appropriate answers for a question or a set of questions. The ability to break down the learned materials into a few categories and examine each category to reach divergent conclusions falls into the category of analysis.

The second highest thinking order, synthesizing, occurs when the DLs are able to use their previous knowledge and newly learned knowledge to produce new knowledge. In this study, the new knowledge refers to how to provide possible solutions which are feasible in the Malaysian context. In doing so, the DLs evaluate all the information they have accumulated through newly learned information, their own prior knowledge, others' knowledge within their e-learning community to tailor to the needs of the local context. The DLs are able to achieve the highest order thinking skills which is evaluation, when they are able to evaluate materials based on certain standards or values in order to create end products.

To surmise, the DE should pose questions which require the DLs to utilize all or almost all higher order thinking skills advocated by Bloom and his colleagues. This is definitely not an easy task. Thus, the DE should allocate a considerable amount of marks and monitor students' participation (Alessi \& Trollip, 1991). As to promote active participation and reduce the students' apprehension level of their linguistic errors, no marks should be deducted if the DLs made any syntactic and morphological errors. The DE should also promote social interactions within the e-learning community so as to foster a sense of community, create social bonding and reduce the feelings of isolation which is common among distance learners ( $\mathrm{Ng}, 2012)$. Apparently, working together as a team would reduce the DLs' stress level and promote fun learning. In addition, the DE's role in maintaining the newly established online community could encourage exchange of knowledge, experience and learning products (Zaihan, 2010).

Stemming from these discussions, it is important that a study in our institution is carried out to identify if e-learning in local context yields similar positive results. Thus far little empirical evidence has been found in local context to corroborate the findings from other countries. This research is also conducted to find the strengths, weaknesses and limitations of this new teaching method in the local context. By doing so, the researcher is able to know its effectiveness and impact on the teaching and learning as well. 


\subsection{Past Studies}

Markel (2001) integrated into her course an online discussion forum in her class at Northern Arizona University. Her students worked in small groups to complete a project. The students participated in the online discussion forum to discuss course content facilitated by further readings from websites and online assignments. The students' participation is independent of their time and location. Her study found that participation in online discussion forums enabled the students to be more responsible in their learning and to become active learners through active participation. Markel asserted that group work played a role in imparting a shared sense of purpose and promoting group identity with a sense of interdependence and belonging. With respect to the role of the teacher, it was argued that the teacher must design a task which is well structured and has clear expectations. To create online identity and promote a sense of responsibility, teachers can make it a practice to have students' names posted along with their comments. She also recognized that at the initial stage, the students would face difficulties due to their unfamiliarity with the web based concept, therefore requiring some initial guidance and coaching. What is probably an important facet of online discussion is the opportunity for those whose voices are seldom heard to interact better with the content of the course and their peers.

In the Malaysian context, Berhanuddin and Mansor (2004) studied online discussion forum used in English as Second Language (ESL) classrooms. They studied the discussions between engineering students from Universiti Tun Hussein Onn (UTHO) and Teaching English as Second Language (TESL) students from Universiti Teknologi Malaysia (UTM). The findings of their study revealed positive results. It was highlighted that their participants favored 'Nicenet' as the platform due its simplicity and user-friendly features. They regard online discussion forum as a platform for the students to practice the target language while discussing various topics and issues ranging from academic to social. The discussion allowed the students to also negotiate and construct knowledge relating to the subject being discussed. In addition asynchronous discussion allowed the participants to provide delayed responses giving them to have ample time to revise their sentences multiple times before posting them onto the plenary. During the revisions, the participants were able to check for grammatical inaccuracies, mechanics and spelling mistakes and typo errors. In a way, the online discussion reduced the pressure on the students in terms of time and fear of being evaluated.

\section{Method}

\subsection{Study Design}

In view of the research questions posed in the study, a case study approach was seen to be appropriate since the researchers' aim was to gain a comprehensive understanding of a situation and process rather than the outcome or product of the phenomena (Merriam 2009). As to ascertain the validity and reliability of this qualitative study, the researchers took several measures as proposed by Merriam (2009). The measures included triangulation, validation of questions for the semi-structured interviews, members check or participants' validation, and adequate engagement of data collection.

The researchers employed three research tools namely the online forum discussion thread, DE's interview responses and DL's interview responses for data triangulation to confirm emerging findings. The researchers used interviews as the main research tools because it concerns behavioral events as recommended by Yin (2009). As for validation of questions the assistance of two experts were sought to review the questions. Both experts are doctorate holders of relevant disciplines and have more than 15 years teaching reading and online courses in ESL context. These experts reviewed the semi-structured interview questions on a few aspects namely clarity, redundancy, readability and completeness. After getting the feedback and discussing with the experts, the researchers reworded, added and deleted the questions so that the questions would be more suitable and more comprehensible to the participants. The transcriptions were returned to the participants for review of the interpretations made. The researchers also spent adequate time in the research site, and the process of collecting and interpreting the data was comprehensive to the point of data saturation. Pseudonyms are used when reporting the findings. It is found also that using pseudonyms reassured the participants that their identity would remain anonymous and whatever they said remained confidential. This also encouraged the participants to respond honestly and accurately (Creswell, 2009).

\section{Research Design}

\subsection{Setting}

In this study, the researcher employed purposive sampling which is generally used in case studies (Cohen \& Manion, 1989). Purposive sampling was selected because the researcher wanted "to discover, understand and gain insight from a sample from which the most could be learned" (Merriam, 2009, p. 79). In other words, this 
set of participants was chosen because they fulfilled the characteristics which the researcher had determined to study and they also served the purpose of this study (Dornyei, 2007). Patton (1990, p. 169) defines purposive sampling as the technique of selecting suitable respondents who could "provide information-rich cases whose study will illuminate the questions under study". This serves the objective of the study, and further to that allowed the researchers to explore the implications associated with the investigation being conducted (Merriam, 2008). The participants of the study were adult distance learners who enrolled in English for Life Sciences (ELS) course, which was a reading course that utilized e-learning to a considerable degree. One element in the course was participation in online forum discussions. The other participants in the study were the course facilitators who taught this course and monitored the online forum discussion. The researcher selected all the participants based on their willingness; the reason being that the respondents' full collaboration was highly needed to ascertain the success of the research. Three facilitators and seven students volunteered to be interviewed.

An academic semester in UKM consists of 14 weeks. From Week 4 to Week 14 during the study, the participants were required to use online forum to answer two sets of questions posted by their facilitator. The initial 2 weeks were used to familiarize the DL with the technology so as to minimize technical glitches. Asynchronous online forum was utilized in this study. The program used was 'Nicenet'. The questions posted were based on two units of the reading materials prescribed in the course, with the first set of questions posted in Week 4 . In the first set of questions, the DLs were required to discuss the topic 'Schizophrenia' whereby they needed to discuss the locals' perceptions towards this mental illness and the treatments taken. In Week 8 , three weeks after the first set of questions were posted, the researchers interviewed the students. In Week 9, another set of questions was posted. This set of questions was about 'Designer Babies'. The DLs were required to take a stance as to whether selecting a baby's gender should be allowed in the Malaysian context and substantiate their stance with reasons. Again, the students were given 3 to 4 weeks to discuss the answers among themselves. Online forum was engaged in order to provide a platform within which the DLs could communicate with each other to answer the questions posted. What needs to be mentioned here is that the activity was aimed at enhancing students' reading comprehension, higher order thinking skills, participation and communicative ability. Therefore, the focus was not on language accuracy. No marks were deducted if the DL made any syntactic and morphological errors.

The researchers interviewed the participants in Week 7 and Week 12. The interview sessions with the students were conducted individually. The facilitators were interviewed individually in Week 14, the final week of the semester. The duration for each interview was between 60 to 90 minutes. The interview responses were transcribed in verbatim. Transcription is a process of transferring the data on the audiotapes into textual forms (Dornyei, 2007; Creswell, 2009). Before the data was analyzed, the researcher listened to the audio-tape and transcribed the verbal report, including non-verbal expressions like pauses, grumbles, hesitations, uncertainties, and others were transcribed. Undoubtedly, some body language or non-verbal expressions namely intonation, stress, paralinguistic factors (acoustic sounds) or non-vocal sounds were missing (Dornyei, 2007). To retain authenticity, no changes were made to the online thread of discussions. The data from the interviews and online forum discussion threads were coded to note emerging themes. The analysis was then checked against the content of the two reading units for accuracy. Data gathered from the interviews and the online forum thread of discussions was then collated. Data triangulation is an important measure to ascertain reliability and validity.

The main objectives of the ELS course were to equip students with relevant reading strategies, linguistic knowledge and vocabulary needed for them to read and comprehend health sciences materials. All of these students were Diploma Holders in health sciences disciplines. The majority were working in hospitals, clinics and municipal councils all over Malaysia. Others are attached to government agencies and corporate sectors. In general, the respondents' age range is between 25-45 years old. English was not the main language of communication both at home and in workplace. All DL participants rated their knowledge on computer and Internet as average.

\section{Findings and Discussion}

The first research question posed in the study was how does online forum discussion create a sense of learning community? Based on the findings, it can be said that that online forum discussion can help foster a learning community among the DLs in ways that required them to read, share and collaboratively construct knowledge and understanding in order to fulfill the task set out in the course. The nature of the activity carried out opened up space for the DLs to better engage themselves with the course (activity at hand) and their peers which led to the creation of a learning community. In the course, the DLs were pushed to read extensively before they could share their reading with the other group members, discuss what they had read and answer the questions posted in the course. One of the students, DL1, claimed that: 
"Actually, online forum requires us to read and search for a lot of information, then only we could post our ideas. So, we need to access many websites to add lah our ideas"

The response above demonstrates that for the DL to write and submit their postings, they had to do extensive reading so that they could substantiate their viewpoints with facts taken from the prescribed reading texts and from other credible sources. What could be examined from the postings in the study is that the students' reading included various sources and authors, namely the main hypermedia given in the course materials, suggested websites prescribed by the course designers, websites which were put under hyperlink in the postings, Quranic verses, hadith and fatwa, summaries and excerpts from lectures, the law, movies, journals and books. There was also input taken from the DLs' own experiences (personal, work and academic), readings of earlier postings, and other relevant reading materials which added value to the discussions as those ideas came from members who were experienced in the subject discussed. What can also be clearly seen is that the information and knowledge obtained by one person were passed on to the others based on the sharing aspect of the activity. This knowledge was not only restricted to the reading subject itself but the working process of accessing the required information; that is the skills involved in using technology to obtain and share information digitally via websites, hyperlinks to movies pertaining to the subject matter and others, as can be evidenced by the following claims:

FROM: DL 7 (01/30/09 7:49 AM GMT-06:00)

SUBJECT:

I think it would be better if I could paste the MRI or CT images of the brain here, anyway you can click to this link. Thank you. http://www.schizophrenia.com/schizpictures.html

FROM: DL6 (03/26/09 12:38 PM GMT-06:00)

SUBJECT: Society's Perception

schizophrenic behaviour is sinful and that mental hospitals do not provide effective treatments" - excerpt from conclusion made in a study on schizophrenia (kota kinabalu 2008).. http://isp.sagepub.com/cgi/content/abstract/54/2/164

\section{MOVIES}

FROM: DL4 (01/10/09 9:20 PM GMT-06:00)

SUBJECT: Split Personality?

The word schizophrenia comes from the Greek words "schizein" which mean to split and "phren" which means the mind. Thus the definition of schizophrenia often is confused with a person with split personalities which is not always the case.

My first encounter with the word schizophrenia was in my primary school days where there is this particular song (can't recall any of the lyrics now) in one of the English books. It's a song about the madness of King Nebuchadnezzar who was a biblical Babylonian king.

Schizophrenia is also well depicted in hit movies such as The Three Faces of Eve (1957) starred by Joanne Woodward, One Flew over the Cuckoos Nest starred by Jack Nicholson, and the most recently A Beautiful Mind (2001) starred by Russel Crowe.

What is important regarding the reading and sharing of information in the online forum mentioned above is the learning which took place from the discussion involved. The nature of the questions posed (topic of discussion played a role here whereby the students were made to think critically, make comparisons and inferences, and construct their own support and reasoning based on their own perspectives and of their friends'. Apart from that, the discussion initiated by the questions found the students recognizing and correcting each others' errors. As one of the DE stated,

"The topic of the discussion should make the students to think critically. By reading extensively they are able to make comparison among the Schizophrenia treatments both locally and internationally. The students are also able to analyze errors when their friend gave wrong statements. Using their own background knowledge working in the hospital, the students are also able to recognize wrong statement stated in the local newspaper on the hypertension treatment. They discuss all these in their online forum discussion".

Looking at the results from the point of view of constructivist theory, the online forum discussion involved a great deal of self-regulated learning via participation in a forum discussion among members. Knowledge was 
constructed collaboratively through sharing of information, constructing support and analyzing different sources and perspectives. In the case of the course, fruitful discussions took place that resulted in new knowledge being constructed, and because the discussions were carried out within a social environment, the knowledge was constructed together in collaboration, and therefore resulting in collaborative learning. This knowledge construction aspect of online forum discussion was echoed by two participants namely DL1 and DL6 during the interview sessions: "one of the means for us to develop our ideas are to discuss all the answers and pour them in the online forum" and "even though 5 entries is enough but I did more than that to disagree and agree with other ideas. I feel belong to the group discussion. I think it's my responsibility to correct others because it's my area. I work in mental ward."

The above finding lends support to Constructivists' belief that learning involves transformation of ideas and information toward solving a task. In addition, the newly discovered knowledge on mental illness, Schizophrenia, (gained from their classmates' responses and extensive reading) could be applied to their work. This also contributed to their motivation level ("The diets are relevant to my psychiatric patients. So I need to add my knowledge on this" and "I enjoy this because it is important information for my patients"). This claim concurs with Nuttal's (2005) viewpoint that motivation is influenced by the text genre, one's ability to comprehend, attitude and socio-cultural environment. This finding confirms Rogers' (2002) viewpoint that adult learners enter an educational activity with a life-centred, task centered or problem centred orientation to learning. To further elaborate, they do not learn for the sake of learning but to perform a task, to solve more problems or to lead a more satisfying life. The online discussion provided a platform on which the students could read about a subject relevant to them and carry out a discussion among fellow classmates. The ideas generated enabled them to learn from one another, especially when the topics discussed were relevant and applicable to their profession and own life circumstances, as the following response illustrates:

"Last time I gave this topic on deciding a baby's gender to on campus students. They were not interested because they were not married yet. However, the adult learners could give a lot of ideas. Most of them are married with kids. They gave examples of personal and professional experience as well. This creates more interesting discussion"). This opinion is also supported by the DL3 (A...if I my interest level is high, I'll surf the websites to find the answer).

This finding concurs with Knowles (1984) notes that adult learners prefer topics they could be applicable to their daily life or professional needs. As learning takes place via participation, the choice of subject is an important one if active participation is expected and encouraged. In the case of the study, the students' participation in the online forum can be seen to help foster the creation of a learning community.

The class members participating in the forum discussion were committed to participate in the forum discussion online, and therefore established a sense of learning community online. In many ways the online forum discussion creates the sense of community by providing motivational values that, as stated by Shackelford and Maxwell (2012), promote interaction, social reinforcement and information exchange that is necessary for learning to take place. One participant, DL3, expressed her views that the discussion made her feel like a full time student since she could communicate with others through cyberspace. Besides social support, online forum also provided some kind of support for the students academically. It was claimed that extensive reading and many attempts at answering the post reading questions enabled the DLs to anticipate the format and question patterns of the final exams ("I'm glad that I read and try many of the given materials and suggested websites, I know the format and improve my vocabulary. It helps me to answer the final exam questions").

DL4 stated that she could write better after constructing and revising her work multiple times. She also reflected that she felt less pressure because she was able to freely revise her work without the presence of the other students. ("... there's nobody in front of me. I feel less pressure. I have ample time to revise and write as many times as I wish"). These DLs also sought assistance from their family members, colleagues and friends.

An important element in developing a good sense of learning community, as evidenced in the study, besides sharing information and knowledge with one another was expanding and confirming upon the ideas of other students. The following example is taken from a particular thread of discussion on the online forum discussion. It is an example showing the activity of sharing and expanding of ideas stemming from the subject of treating Schizophrenia in Malaysia. 
FROM: DL4 (04/10/09 9:19 PM GMT -06:00)

SUBJECT: RE: Problem of treating schizophrenia in Malaysia?

Clinical efficacy of Schizophrenia treatment:

Only effective in controlling the positive symptoms acute Schizophrenia (high dose). Difficult to get the right dose from the typical drugs and less atypical drugs are developed (costly) and can be given IV. Treatment in long and continuous period of time to avoid recurrent (important to carry out daily routine). Not affective for negative Schizophrenia symptoms. About 40\% chronic patients cannot be controlled by those drugs (Clozapine treatment needs agranulocytosis monitoring). Psychoterapeutic drugs are to treat symptoms of Schizophrenia ONLY. MUST have psychotherapy treatment.

It was also found that toward the end of the online forum, a few of the students even managed to summarize or paraphrase their classmates' opinions using their own words. This is good news as far as the writing and use of the language are concerned. Berhanuddin and Mansor (2004) found this to be true as well stating that online discussion provides room for language practice. However, the act of summarizing and paraphrasing taking place during the course suggests comprehension of subject matter materials, and thus the ability to confirm upon each others' ideas. . The following excerpts reveal that the students had made attempts to go through the long thread of discussion and showed their comprehension of those entries in their summaries (refer to the following episodes).

\section{FROM: DL5 (03/07/09 12:57 AM GMT -06:00) Send a personal message to MA]}

\section{SUBJECT:}

hi again...

After long discussion, most of us agreed that 'designer babies' arguments can be divided to: (1) arguments for creating 'designer babies' and (2) arguments against creating 'designer babies'. Either arguments have its pro and con. As per discussed by our friends in this forum earlier on, 'designer babies' only reasonably designed if:

(1) Some couples are not able to have children because their children will have a genetic disease and die before they are born or when they are very young. Techniques used to change the genetic make-up of the embryo allow these parents to have a child.

(2) Spare part children? In a few cases where parents have had one child with a serious blood disease, they have used IVF to select embryos so that they can have a second child that can act as a future, tailor-made blood or bone marrow donor. In these cases when the child is born he or she will be healthy and can help their older brother or sister stay well.

When the student participants carried out the discussion, they needed to substantiate their content with facts. This can only be done by reading earlier postings, other relevant reading materials and relating those to their personal or working experiences. Consequently, a more fruitful discussion took place, involving construction of knowledge which ultimately led to collaborative learning. This knowledge construction aspect of online forum discussion was echoed by two participants namely DL1 and DL6 during the interview sessions: "one of the means for us to develop our ideas are to discuss all the answers and pour them in the online forum" and "even though 5 entries is enough but I did more than that to disagree and agree with other ideas. I feel belong to the group discussion. I think it's my responsibility to correct others because it's my area. I work in mental ward.")

The online forum also helped students to be more aware of their own ideas and assertions in relation to others, using that awareness to help each other out. This appears to be another positive aspect of a learning community. The earlier feedback from DL1 and DL6 illustrates this benefit:

"One of the means for us to develop our ideas are to discuss all the answers and pour them in the online forum" and "even though 5 entries is enough but I did more than that to disagree and agree with other ideas. I feel belong to the group discussion. I think it's my responsibility to correct others because it's my area. I work in mental ward." 
DL 4 further stated that:

"OK. The online forum really helps me. First, sometimes we think that we're right but when others are against our opinion then only we realize our mistakes".

In this case, elements of thinking and sense of learning community are inter-related. First, relating one's ideas with another illustrates a higher level of thinking skill involving application (Bloom, 1956). Second, the need to help other group members suggests the existence of a sense of belonging, much like that defined by McMillan and Chavis (1986), and the need to commit to each others' well-being (in the course). The online forum discussion has managed to create a sense of learning community among the students through social bonding and a connection of ideas.

Through participation in the forum and sharing of ideas, the student participants realized that some of their ideas, including terminology or particular theme, could potentially be reviewed and re-interpreted (perhaps also misconceived or misinterpreted). The idea that their responses or entries (the writing) are to be shared with others and for others to understand helps create that sense of community envisaged by proponents of online forum. As the participants knew that their discussions would not be lost in cyberspace, they were more encouraged to participate, especially when the support was there. It is safe to conclude that the participants were motivated to participate because of the human aspect offered by the online forum. The finding supports Berhanuddin and Mansor's (2003) study on UTHM and UTM students' experience as helping them build social-cultural understanding of each other via the online discussions.

The findings also point to the important role of distance educators (DE). In the above case, the DE can be said to have succeeded in stimulating the students' thinking skills as advocated by Bloom et al. (1956), Boyd and Murphrey, (2002) and Cheong (2008). When the students carried out their discussions, they had to read both intensively and extensively, explain, share and complement each other's understanding. Besides comprehension, the educator had also accomplished the task of encouraging the students to employ higher order thinking skills of application. The discussion thread provides evidence of the students' ability to relate new information learned with their previous knowledge and apply it in new and concrete situations to solve a problem. In the course, the students discussed possible ways to solve the problems of Schizophrenia and selecting babies' gender. As the proposed ideas, opinions and possible solutions were to be based on Malaysian context, the students had to evaluate each other's input and responses as well as ensuring that suggestions made conform to Malaysians values and culture.

On another aspect of online forum, for some students the motivation to participate was slightly extrinsic in nature. According to the interview responses given by both DL and DE, DE should allocate marks to encourage the DL in answering the questions and then discussing the answers in the online forum. This statement is derived from the individual response in the semi-structured interviews, (Actually, I join online forum because there's marks there. I need to do it to obtain marks. If I do not do it I do not get any marks, so it's better rather than do not get any marks at all). One of the DEs mentioned that if there were no marks allocated, the DL would not have put as much effort in reading the unit,

"My students mentioned that they read Unit 4 which is on 'Schizophrenia' thoroughly because they need to discuss it in the online forum. Not only that they read the prescribed reading materials, I also see that they put much effort to read from other reading materials. The students provide website addresses and titles of books in their discussion thread"

This finding corresponds to Alessi and Trollip's (1991) assertion that marks provision is important to motivate the DLs to write.

In summary, the online forum discussion created a sense of learning community among the group members as they were willing to read, share and discuss their readings, expand and confirm upon each others' ideas and arguments in order to complete the task given in the course. Going back to the first research question posed in the study, that is how online forum discussion creates a sense of learning community, it can be said based on the findings obtained that online forum creates a sense of learning community by creating a much needed space for DLs to become more engaged with the course and with their fellow course mates. This engagement paved the way for better reading (of the texts and other materials), and better understanding of the subject matter. For much of the time, knowledge was constructed along the way through the reading of each others' postings, revisiting each others' ideas, and synthesizing and summarizing ideas, reasoning and constructing support. In addition the social process involved in the forum discussion enhances interaction and connection among the participants, as can be demonstrated by the positive feedback given by the participants regarding the online discussion and the support it gave them. 
As for the second research question regarding the educator's role in maintaining an e-learning community, findings show that educators need to provide scaffolding and support throughout the activity. At the early stage motivation and positive reinforcements are important for successful participation. In the case of the study, the teacher provided positive comments like 'good' and 'that's correct' and emoticons like 'smiley' to induce greater participation among the DLs. Positive reinforcement could reduce barriers between DE and DL. The DE should also encourage students to do the same when responding to others' entries. DE2 mentioned that, "When I praised the students, they would respond by saying Thank You. By confirming their answers, they would feel more confident with their level of understanding". The response is similar to the interview responses given by DL3 and DL4:

"When the facilitator responded positively to my comment or posting, I know that she keeps track with our discussion. Her response makes me feel confident with my comprehension because sometimes I am not sure if my comprehension is correct or not"

"When the facilitator gave further comments, I realize that she monitors our discussion. I feel happy because I know she keeps track with our discussion and do not leave us alone"

Participants who felt excited with the prospect of improving their reading performance were more motivated to do further reading and to continue responding to their classmates' postings. Monitoring the students' interactions and checking to see if answers are correct are also important for the DE to do as these steps can ensure that the students participate actively in the discussion. Positive, enriching and frequent interactions could sustain positive learning environment which affect the success of an e-learning program (Tobin, 2001).

The DE could also monitor 'absences' in the online discussion to further the on-going interactions, and identify problems. Many of the Des in the study were already doing that ("I called XXX to ask her why she did not participate in the discussion. Then only that I discover that she does not know how to even log on to the discussion. Therefore, I had to teach her to log on step by step over the phone. Then, only she started posting her answers"). This finding is an important one as DLs given their age and exposure to technology may be inhibited to use technology and could potentially hinder participation and learning. The students' lack of knowledge of technology could cause them to become apprehensive of the new technology. A DL who has left the educational setting for many years expressed his feelings regarding the issue, believing that he lacked the computer skills required ("I hardly use computer at both my workplace and home I don't know how to use Internet. My classmates live far from me. I feel isolated and lonely. I don't have anybody to ask questions").

In view of possible problems relating to technology use, the teacher needs to provide personal coaching to assist students better. This finding supports the assertion of Bernhardt et al. (1989) that computer-based instruction may not be well received by students who lack computer knowledge. These groups of students tend to prefer the traditional mode of learning and may lack competence in the use of computer which may lead to feeling of isolation. It has been found that feeling of isolation is common among distance learners in Malaysia (Dzakiria \& Walker, 2002). This will eventually lead to frustration especially when confronted with problems that they could not solve independently. Moreover, Rogers (2002) stated that some adult learners feel hesitant to retool themselves with new knowledge since they are already in a 'comfortable zone'.

The frustration felt is also due to feeling lack of competence in target language proficiency and subject matter. The participants in the study expressed embarrassment over their own language errors ("I feel shy") and wished not to be ridiculed if the contents of their postings were inaccurate and contained a lot of grammatical errors ("When I post something which is inaccurate, they will laughlah"). For some of the students, this 'fear' produced something more positive. They felt more compelled to put much time and effort surfing credible websites and making sure that they fully comprehend what was said in the websites before composing their postings. These efforts involved reading the websites suggested by their classmates and searching for other relevant websites to add on to their classmates' contents and ideas. Thus, despite their perceived 'deficiencies', they were capable of completing the online forum task successfully - which was to look at and analyze a problem from various angles and perspectives. With respect to cognitive theory of learning, it can be seen that for these students, the learning process is a sequence. They equipped themselves with the relevant knowledge first before attempting to produce an output.

Perceived deficiency in the language and subject also produced negative consequences. Some students in the courses withdrew themselves from the discussion during the first two weeks stating lack of competence in the English language. In this case, the DE's support is crucial for building students' confidence such as providing language scaffolding in the form of notes on language structures students could refer to when constructing their sentences and revising. This is clearly mentioned by three of the DLs, 
“In the beginning, I don't want to say anything because my English is bad. But when I read others' postings and their level is just like mine, then, only I am brave to join".

"I refer to the notes and self- check my sentences. My English is weak and I don't want my friends to laugh at my sentences" and

"The students were able to go through the notes at their own pace and become autonomous learners especially when they need to submit their views in the online forum"

Most student participants added that they had forgotten a lot of grammar since they left school many years ago. In that respect, they felt that face to face tutorials were better for learning grammar because some of them could not fully comprehend the language input online from the websites. Nonetheless the DLs were prepared to improve upon their English. Statements such as "I need to expand my knowledge" and "In order to improve my English I need to read many articles written in English to improve my vocabulary" indicate that there existed motivation and interest among the DLs to improve their English as well as subject knowledge. Again teacher scaffolding is needed to sustain the motivation among the DLs.

In order to overcome the inferiority issue to do with the language, the DL participants suggested that the class which consisted of 22 students should be divided into small groups of 6 . The student participants mentioned that with smaller groups the level of apprehension could be reduced. Markel (2001) suggested that a group size of 5 or 6 students helps ease communication and build confidence as well as promote better sense of responsibility and more sense of belonging in the process of imparting and constructing knowledge.

\section{Implications}

The study indicates that online forum discussion could promote a sense of learning community among the group members. However, the degree of success using this new approach could only be achieved with proper guidance from the educator. An educator who seeks to employ the usage of online forum in their language class needs to design a set of questions or instructions that could promote and facilitate all levels of cognitive skills. The educator should consider the students' age, language ability, previous knowledge, interests and needs when constructing the questions or instructions. In this study, since the students involved were adult learners, the questions should emulate their working environments. The type of questions should promote the students to have both intensive and extensive discussions in order to solve a problem or to build new creations which are relevant and appropriate to local context. As to ascertain a non-threatening environment in the online forum especially to distance learners, the educator should ensure that each group should not exceed six members, continuously provide constructive feedback, monitors students' participation, prevent any students from becoming lurkers and encourage active participation. Only with healthy and conducive working environment, the adult learners will feel at ease and are willing to commit themselves with the discussions. Commitments could be evidenced when through the students' spend considerable amount of time reading both intensively and extensively, develop each other's understanding, collaborate with each other to solve a problem or an issue.

\section{Conclusion}

In conclusion, it is safe to conclude that use of online forum discussion does create a sense of learning community among the adult distance learners in the study. To some extent, the nature of the activity involved, the reading topics and the readiness of the learners to use new technology in learning are important determinants to the success of the online forum discussion. What this implies is that some scaffolding needs to be provided, either in the form of good questions that encourage discussion, or encouragement in the form of confidence building, assistance and for some, marks allocation. In this case the educator (DE) plays an important role in maintain the discussion, and providing the support needed by adult learners in academic, motivational and social sense.

\section{References}

Alessi, S. M., \& Trollip, S. R. (1991). Computer based instruction: methods and development (2nd ed.). Englewood Cliffs, New Jersey: Prentice Hall.

Berhanuddin, M. S., \& Mansor, W. F. A. W. (2004). Participation in an online forum. Internet Journal of e-Language Learning and Teaching, 1(2), 33-47.

Cheong, L. W. (2008). A Study of Students' Perceptions and Attitudes Towards ESL Writing Using Computer-Based Learning Materials. Readings in Online Language Learning and Teaching. Research and Practice.

Cohen, L., \& Manion, L. (1989). Research Methods in Education (3rd ed.). London: Routledge 
Collis, B., \& Moonen, J. (2006). Flexible Learning in a Digital World. London: Routledge Taylor \& Francis Group.

Creswell, J. W. (2009). Research Design: Qualitative, Quantitative and Mixed Methods Approaches (3rd ed.). Thousand Oaks CA: SAGE Publications.

Dornyei, Z. (2007). Research Methods in Applied Linguistics: Quantitative, Qualitative and Mixed Methodologies. Oxford: Oxford University Press.

Dudeney, G., \& Hockly, N. (2007). How to...teach English with Technology. Edinburgh: Pearson Longman.

Dzakiria, H., \& Walker, R. (2002). Teacher is Always There, but Isn't. Students' Perspectives on Learning Support: A plea for Knowledge. Paper presented at International Symposium at Sede Spain.

Hisham, D., \& Rozhan, M. I. (2003). Teacher-learner interactions in distance education: A case of two Malaysian Universities. Turkish Online Journal of Distance Education, 3(3).

Inoue, Y. (2007). Online Education for Lifelong Learning. London: Information Science Publishing. http://dx.doi.org/10.4018/978-1-59904-319-7

Jonassen, D. H., \& Campbell, J. P. (1994). Learning with media: Restructuring the debate. Educational Technology: Research and Development, 42(2), 31-39. http://dx.doi.org/10.1007/BF02299089

Jordan, A., Carlile, O., \& Stack, A. (2008). Approaches to Learning: A Guide for Teachers. New York: McGraw Hill.

Kadir, R. A., \& Din, R. (2006). Computer mediated communication. Jurnal Pendidikan, 31, 41-51.

Knowles, M. S. (1984). Introduction: The Arts And Science Of Helping Adults Learn. Andragogy in Action: Applying Modern Principles of Adult Learning. San Francisco: Jossey Bass.

Lantolf, J. P., \& Thorne, S. L. (2006). Sociocultural Theory and the Genesis of Second Language Development. Oxford: Oxford University Press.

Markel, S. L. (2001). Technology and Education Online Discussion Forums: It's in the Response. Online Journal of Distance Learning Administration, 4(2).

Martin, G., Bohl, O., \& Winand, U. (2007). A case study on education networks and brokerage. In C. S. Ramesh, \& M. Sanjaya (Eds.), Cases on Global E-Learning Practices: Successes and Pitfalls (pp. 22-34). Ideagroup: United Kingdom.

Merriam, S. B. (2009). Qualitative Research: A Guide to Design and Implementation. San Francisco: Jossey-Bass.

Nuttall, C. (2005). Teaching Reading Skills. Oxford: Macmillan Publishers.

Patton, M. Q. (1990). Qualitative Evaluation and Research Methods (2nd ed.). Newbury Park, CA: SAGE.

Ramesh, C. S., \& Sanjaya, M. (2007). Global E-Learning Practices: An Introduction. In C. S. Ramesh, \& Sanjaya (Eds.), Cases on Global E-Learning Practices: Successes and Pitfalls (pp. 1-12). United Kingdom: Ideagroup Inc. Retrieved from http://www.scribd.com/doc/20071798/Cases-on-Global-E-Learning -Practices-Successes-and-Pitfalls

Rogers, A. (2002). Teaching Adults. London: Oxford University Press

Shackelford, J. L., \& Maxwell, M. (2012). Sense of community in graduates online education: Contribution of learner to learner interaction. The International Review of Research in Open and Distance Learning, 13(4).

Toh, S. C. (2003). The Design and Developments of a Constructivist Multimedia Learning Environment (CMLE). The Univesiti Sains Malaysia Experience. Proceeding at the $16^{\text {th }}$ Educational Teachnology Convention (pp 66-75).

Vygotsky, L. S. (1978). Mind and Society. Cambridge, MA: Harvard University Press.

Yin, R. K. (2009). Case Study Research: Design and Methods (4th ed.). Los Angeles: SAGE Publications.

Zaihan, A. F. (2010). Blended Learning in Higher Education Institution in Malaysia. Proceedings of Regional Conference on Knowledge Integration in ICT 2010. 


\section{Copyrights}

Copyright for this article is retained by the author(s), with first publication rights granted to the journal.

This is an open-access article distributed under the terms and conditions of the Creative Commons Attribution license (http://creativecommons.org/licenses/by/3.0/). 